\title{
A new tool for the simulation of different nuclear fleets at equilibrium
}

\author{
Heddy Barale*, Camille Laguerre, Paul Sabatini, Fanny Courtin, Kévin Tirel, and Guillaume Martin \\ DES/IRESNE/DER/SPRC/LE2C, CEA Cadarache, 13115 Saint Paul-lez-Durance, France
}

Received: 16 July 2021 / Received in final form: 18 August 2021 / Accepted: 24 November 2021

\begin{abstract}
Scenario simulations are the main tool for studying the impact of a nuclear reactor fleet on the related fuel cycle facilities. This equilibrium preliminary study aims to present the functionalities of a new tool and to show the wide variety of reactors/cycles/strategies that can be studied in steady state conditions and validated with more details thanks to dynamic code. Different types of scenario simulation tools have been developed at CEA over the years, this study focuses on dynamic and equilibrium codes. Dynamic fuel cycle simulation code models the ingoing and outgoing material flow in all the facilities of a nuclear reactor fleet and their evolutions through the different nuclear processes over a given period of time. Equilibrium fuel cycle simulation code models advanced nuclear fuel cycles in equilibrium conditions, i.e. in conditions which stabilize selected nuclear inventories such as spent nuclear fuel constituents, plutonium or some minor actinides. The principle of this work is to analyze different nuclear reactors (PWR, AMR) and several fuel types (UOX, MOX, ERU, MIX) to simulate advanced nuclear fleet with partial and fully plutonium and uranium multi-recycling strategies at equilibrium. At this first stage, selected results are compared with COSI6 simulations in order to evaluate the precision of this new tool, showing a significant general agreement.
\end{abstract}

\section{Introduction}

Scenario studies can be used to explore future options of the nuclear energy development, investigating the advantages and disadvantages, technological constraints, costs and overall attractiveness of different fuel cycles and reactor fleet developments. To further improve nuclear fuel use and nuclear waste management, advanced nuclear fuel cycles involving innovative reprocessing plants and reactors are being evaluated. As highlighted by the French PPE (Programmation Pluriannuelle de l'Énergie) [1], managing the spent fuel arising from nuclear power plants until its reuse or disposal is an important step of the nuclear fuel cycle and constitutes the so-called back-end. It is essential to address spent fuel management properly because this issue directly involves the sustainable development of nuclear energy, the nuclear non-proliferation, the nuclear energy costs, the natural resource utilization etc.

In order to assess the performances of these nuclear fuel cycles, the equilibrium simulation tool SEPAR (Equilibrium Simulator of Advanced Reactor Parks) has been recently developed at the Department of Reactor Studies (DER) at CEA Cadarache. It relies on a neural network

\footnotetext{
* e-mail: heddy.barale@cea.fr
}

approach [2] to estimate the equilibrium material composition and fluxes for each isotope to and from reactors, enrichment and reprocessing facilities. It models advanced nuclear fuel cycles in equilibrium conditions, i.e. in conditions which stabilize selected nuclear inventories such as spent nuclear fuel constituents, plutonium or some minor actinides. One of the major innovations brought by SEPAR is the calculation of the equilibrium of the material flows in a reactor fleet, this aspect is absent from the usual dynamic scenario simulation codes (such as COSI [3]), which on the other hand allows to simulate the transition from one fleet to another, year after year.

France is a major player in the recycling of nuclear materials in the world since it recycles plutonium from its spent Low Enriched Uranium (LEU) fuel in the form of MOX fuel. Recycling of the fissile uranium remaining in spent LEU fuel has also been undertaken in the past in the form of ERU fuel, and is expected to resume over the next decade [4]. However, the recycling of spent fuel remains incomplete today. To advance the recovery of materials and the reduction of nuclear waste, it is necessary to study advanced reactor fleets that use innovative recycling plants and/or new reactor concepts. For example, in the medium term, the renewal of the French fleet by a new generation of EPRs offers the opportunity to deploy new fuel management systems, capable of recycling all 
the spent fuel in the fleet [5]. SEPAR has the advantage of being extremely fast in calculation time, this feature allows the study and the future complete validation of the code to different reactors and related fuel cycle strategies at steady state. The fuel types took in consideration during this study are the Uranium OXide (UOX), the Mixed OXide (MOX), Enriched Reprocessed Uranium (ERU) and the MOX Enriched Uranium Support also known as MIX. This paper focuses on the application of SEPAR to different fuel options four different strategies: the UOX - MOX mono-recycling of $\mathrm{Pu}$ (the actual French strategy [6]), the UOX - ERU mono-recycling of U, the UOX - MIX full multi-recycling of Pu and the UOX - MOX - AMR partial multi-recycling. In Section 2 the first description of the SEPAR tool is presented. In Section 3 an analysis of the SEPAR results concerning the four aforementioned cases is proposed, as well as a primary comparison/validation with COSI6.

\section{Methodologies}

The modeling of a complex system such as a nuclear energy system requires physical modeling of all major processes occurring in the system. A nuclear energy scenario is generally defined by the components of the system, i.e. enrichment, fuel fabrication, reprocessing facilities and reactors. The scenario aims to forecast the evolution or equilibrium state of the system depending on input parameters. The evolution is mostly captured in the material fluxes between the different components of the system.

Different types of scenario simulation tools have been developed, this study focuses on dynamic and equilibrium codes. Dynamic fuel cycle simulation codes model evolving nuclear fuel cycles, and calculate nuclides inventories and material flows in each unit of the cycle over a given period of time [7]. In equilibrium simulation the study is made at steady state, defined by the fact that all the material fluxes, at every step of the recycling processes are constant and that the isotopic composition of the fuel is the same at each cycle [8].

\subsection{Equilibrium searching tool: SEPAR}

SEPAR is a calculation module that simulates the operation of a nuclear reactor fleet and its associated fuel cycle facilities in a steady-state regime. It is developed by SPRC (Reactor Physics and fuel Cycle Service) at the IRESNE Institute of the CEA/Cadarache. SEPAR is used to size nuclear fleets that operate a total or partial reprocessing of irradiated fuels. It characterizes recycling fleets with respect to the services they may provide in terms of isotopic streams at cycle level. This may concern the management of recyclable materials or waste, such as the reduction of a plutonium inventory or quantities of minor actinides to store in-depth, etc.

SEPAR development follows a first study that showed the interest in this method on EPR - SFR symbiotic fleet [9]. Currently, SEPAR-based studies aim to quickly provide detailed characteristics of advanced fleets under

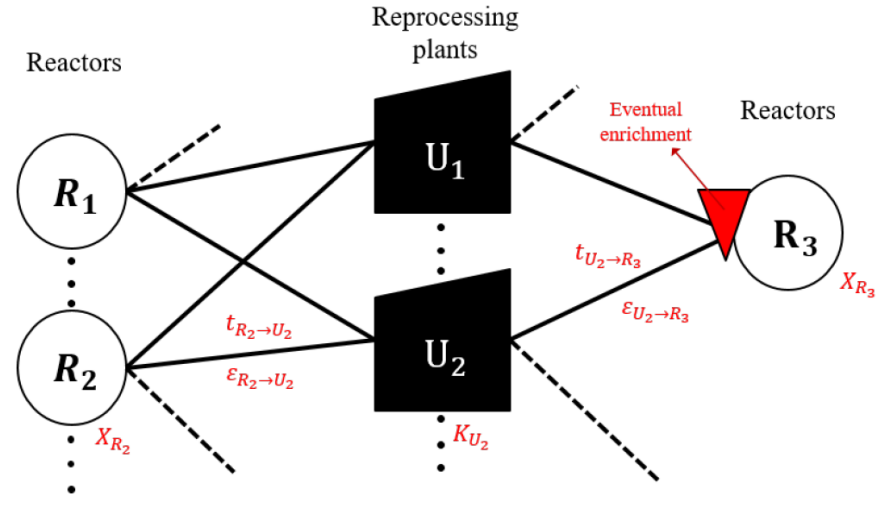

Fig. 1. SEPAR working scheme.

various operating conditions. In particular, it can highlight and explain the effects of prospective fuel batches that may be operated in any concept of existing or prospective nuclear reactors.

The SEPAR module is integrated into a code environment comprising:

- upstream level: any irradiation code able to simulate the fuel composition after irradiation. These results feed SEPAR, which then builds neural network meta-models for irradiation as well as equivalence model for fresh fuel composition.

- Equilibrium level: SEPAR is the module for material balance calculations, the system of non-linear equations is solved applying the GNU Scientific Library (GSL) using the Broyden solver [10]. Additional calculation modules allowing access to fleet performance beyond material balances were added at this stage.

- Downstream level: once steady-state fleets are characterized, they can be introduced into dynamic fleet simulations, for instance using the CEA scenario code COSI6. At this stage, economic or environmental indicators in SEPAR are planned to be investigated.

Figure 1 illustrates how SEPAR schematizes an elementary nuclear system. $X$ represents the fuel batch fraction, $K$ is the isotopic composition treatment function at the reprocessing stage, $t$ defines the transfer times between different facilities, while $\epsilon$ characterizes the transferred material fuel fraction between them.

How SEPAR works can be explained with an elementary example concerning only 2 isotopes. This example is described by the system of differential equations in equation (1), in which $B$ is the branching factor for the decay of the parent isotope $p$ to the daughter isotope $i$ and $\lambda$ is the isotope decay constant.

$$
\left\{\begin{array}{l}
\frac{d m_{p}}{d t}=-\lambda_{p} m_{p} \\
\frac{d m_{i}}{d t}=-\lambda_{i} m_{i}+B_{p i} \lambda_{p} m_{p} .
\end{array}\right.
$$

The solution to this equilibrium problem is well known, equation (2) represents the evolution of the daughter 
nucleus:

$$
m_{i}(t)=B_{p i} \frac{\lambda_{p}}{\lambda_{i}-\lambda_{p}} m_{p}^{0}\left(e^{\lambda_{p} t}-e^{\lambda_{i} t}\right)+m_{i}^{0} e^{\lambda_{i} t}
$$

here, $m_{i}^{0}$ and $m_{p}^{0}$ denote the initial masses of daughter and parent nuclei respectively. An analogous expression can be derived for the parent nucleus.

Since the evolution of spent fuel from the reactor to another use in the reactor is not a simple decay, but it consists of different procedures as reprocessing, the expression becomes more complicated. The process can be divided into two steps: from the reactor to the reprocessingstep (Eq. (3)) and from the reprocessing-step back to a reactor (Eq. (4)). Given the cooling and fuel fabrication times (respectively $t_{R_{2} \rightarrow U_{2}}, t_{U_{2} \rightarrow R_{3}}$ ), the evolution for both periods becomes:

$$
\begin{aligned}
m_{i}\left(t_{R_{2} \rightarrow U_{2}}\right) & =B_{p i} \frac{\lambda_{p}}{\lambda_{i}-\lambda_{p}} m_{p}^{0}\left(e^{\lambda_{p} t_{R_{2} \rightarrow U_{2}}}-e^{\lambda_{i} t_{R_{2} \rightarrow U_{2}}}\right) \\
& +m_{i}^{0} e^{\lambda_{i} t_{R_{2} \rightarrow U_{2}}} \\
m_{i}\left(t_{U_{2} \rightarrow R_{3}}\right) & =B_{p i} \frac{\lambda_{p}}{\lambda_{i}-\lambda_{p}} m_{p}^{0}\left(e^{\lambda_{p} t_{U_{2}} \rightarrow R_{3}}-e^{\lambda_{i} t_{U_{2} \rightarrow R_{3}}}\right) \\
& +m_{i}^{0} e^{\lambda_{i} t_{U_{2}} \rightarrow R_{3}}
\end{aligned}
$$

the initial isotope masses are not the same in both equations, because during the reprocessing both parent and daughter nuclei have decayed and/or accumulated, but also have been separated completely or partially during reprocessing. For the mass of isotope $i$ having been produced due to the decay of $p$ during the reprocessing time, a decay factor $\exp \left(-\lambda_{i} * t_{R_{2} \rightarrow U_{2}}\right)$ has been introduced on the produced quantity accounting for the mass that is going to decay during fuel fabrication and by the amount that will be lost in reprocessing. Similarly, during the fuel production, $\exp \left(-\lambda_{p} * t_{U_{2} \rightarrow R_{3}}\right)$ takes into account that during reprocessing, the parent isotope has been depleted due to decay and it might also have been removed during the reprocessing process.

SEPAR is needed to explore in a systematic (on different fleets), rapid (in execution time) and precise (in results) manner, different nuclear reactor fleets at equilibrium. As seen before, the main elements of the dataset are fuel batches in reactor and reprocessing lines, linked together to define a fleet and its cycle. The actual SEPAR outputs consist in the number of reactors in the fleet, and the isotopic compositions of ingoing and outgoing fuels. Although the precision of SEPAR awaits evolutions, this new equilibrium searching tool currently allows the exploration of this domain as a new knowledge domain.

\subsection{Dynamic code: COSI6}

Since 1985, the CEA has been developing the simulation software COSI to study different trajectories of nuclear fleet evolution and provide technical elements to decision makers [3]. The principle of COSI6, including the typical composition of the data set, is exposed in Figure 2.

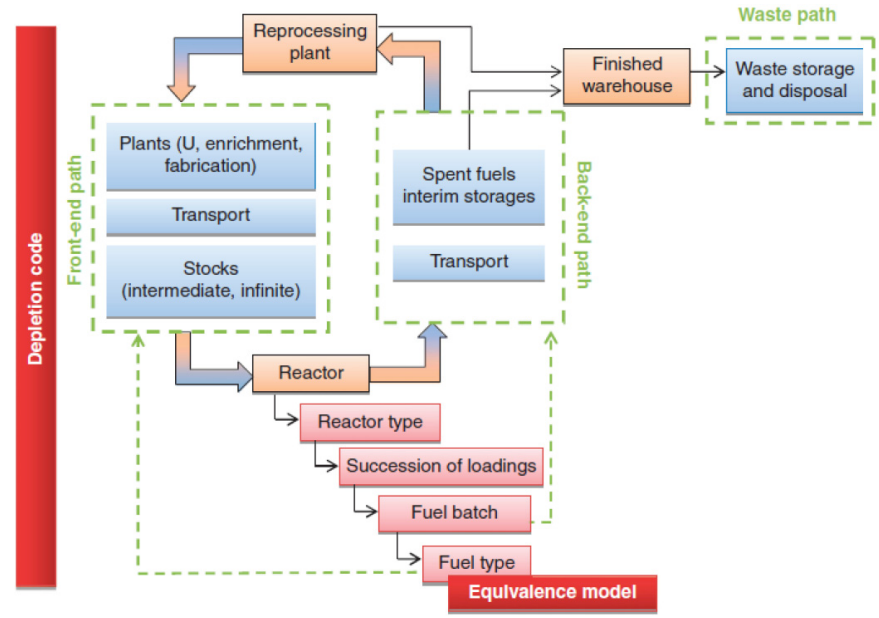

Fig. 2. COSI6 operating diagram.

Table 1. Main characteristics of the reactors featured in the examples.

\begin{tabular}{ll} 
GENIII PWR reactors (UOX, MOX, ERU) \\
\hline Thermal power (MWth) & 4592 \\
Electrical power (MWe) & 1653 \\
Full core mass (t) & 129 \\
Burnup (GWday/t) & 55 \\
EFPD & 1545 \\
Load factor & 0.83 \\
Fuel fractioning & 3 \\
UOX enrichment (\%) & 4.58 \\
\hline
\end{tabular}

COSI6 provides a detailed computation of the materials balances, including the computation of $\mathrm{Pu}$ content or ${ }^{235} \mathrm{U}$ enrichment entering the fuel fabrication, based on socalled equivalence model. In COSI6, the CESAR code [11] is used for the in-pile calculations. It solves the differential equation systems that describes the fuel evolution in pile (irradiation model) from 1-group cross sections libraries.

In this study, COSI6 is applied for the comparison and validation of the UOX - MOX mono-recycling and UOX - ERU mono-recycling scenarios. The following steps of the SEPAR/COSI6 validation include the simulation of partial and fully recycling of uranium and plutonium fuel strategies. The results of COSI6 constitute a reference regarding the new developed tool for automatic research of fleet equilibrium states.

\subsection{Fuel and reactor simulation}

The main characteristics of the reactors involved in the following simulations are compiled in Table 1. The majority of fuels used in the simulations are assumed to reach a final burnup of $55 \mathrm{GWd} / \mathrm{t}$, all cores are supposed to have a mass of $129 \mathrm{t}$, with 4592 MWth of thermal and 1653 MWe of electrical power. The fresh UOx isotopic composition is presented in Table 2. In spent fuel, all uranium isotopes with mass numbers ranging from 232 to 238 are present in varying proportions. 
Table 2. UOx fresh isotopic composition (heavy metal weight fraction).

\begin{tabular}{ll}
\hline Isotopes & Isotopic composition [\%] \\
\hline${ }^{234} \mathrm{U}$ & 0.04 \\
${ }^{235} \mathrm{U}$ & 4.58 \\
${ }^{238} \mathrm{U}$ & 95.38 \\
\hline
\end{tabular}

Different from the conventional MOX assembly, MIX assembly [12] is composed of fuel rods with fixed $\mathrm{Pu}$ content ( $8 \%$ in our case as mentioned in [13]), completed by enriched uranium support to counter-balance the $\mathrm{Pu}$ isotopic degradation. MIX also known as MOX/EUS (MOX Enriched Uranium Support), is studied at CEA within the framework of a quadripartite (Orano, Framatome and EDF) work program in which each partner is a study operator. MIX fuel is a potential method of establishing multiple recycles of plutonium in PWRs without the technical restrictions that affect conventional MOX fuel in this situation, as stated in the French PPE.

\section{Result}

An equilibrium study can be used to determine the reactor fraction which leads to break-even in regard to plutonium or stabilization of spent fuel inventory. The reactor fraction is one essential factor which makes a nuclear fleet a net production or consumption of plutonium.

During the simulations, the required power is $61.2 \mathrm{GW}$ of installed capacity, leading to a fleet comprises a total of 37 reactors. The result presented are based on the reference case in which the UOX assemblies are subjected to a cooling time of 10 years and MOX/ERU/MIX fuels are produced and introduced back into the reactor 2 years after the UOX fuel has been reprocessed.

\subsection{UOX-MOX mono-recycling}

A schematic representation of the UOX - MOX cycle option is shown in Figure 3. SEPAR calculates the batch fractions of the UOX and MOX reactors with the final aim of a plutonium vector stabilization of the MOX fresh fuel. These batch fractions are then normalized to the corresponding number of nuclear reactors in the fleet, leading to the calculation of the annual natural uranium consumption and the fuel fabrication and reprocessing capacity corresponding to the UOX - MOX plutonium mono-recycling strategy analyzed.

During this exercise, the choice was to compared the main SEPAR outputs with COSI6. A UOX - MOX nuclear fleet has been simulated in COSI6 using the same SEPAR input of Table 3. The dynamic code COSI6 requires a more detailed characterization of the fuel cycle strategy adopted, as the exact number of each reactor type, the fuel fabrication capacity, the fuel reprocessing capacity etc. Even if these data are introduced in COSI6 as inputs, they are not constant values over the time, because they're dependent on the material disponibility and requirements.

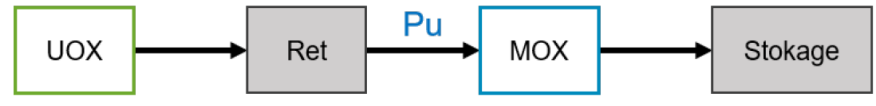

Fig. 3. Fuel cycle of a UOX - MOX fleet.

Table 3. SEPAR output for the UOX-MOX monorecycling option.

\begin{tabular}{lll}
\hline Results & UOX reactor & MOX reactor \\
\hline Reactor fraction & 0.906 & 0.094 \\
Number of reactor & 33.5 & 3.5 \\
Nat. U consumption (t/y) & 7209.5 & 0.0 \\
Fuel fabric. capacity (t/y) & 848.5 & 88.0 \\
Fuel reproc. capacity (t/y) & 848.5 & 0.0 \\
\hline
\end{tabular}

Table 4. COSI6/SEPAR comparison of fresh MOX fuel $\mathrm{Pu}$ vector for the UOX-MOX mono-recycling option (heavy metal weight fraction).

\begin{tabular}{llll}
\hline Isotopes & SEPAR & COSI6 & Rel. Diff. [\%] \\
\hline${ }^{238} \mathrm{Pu}$ & 0.030932 & 0.031612 & 2.2 \\
${ }^{239} \mathrm{Pu}$ & 0.515383 & 0.519674 & 0.8 \\
${ }^{240} \mathrm{Pu}$ & 0.273766 & 0.271727 & 0.8 \\
${ }^{241} \mathrm{Pu}$ & 0.086640 & 0.085141 & 1.8 \\
${ }^{242} \mathrm{Pu}$ & 0.084493 & 0.082932 & 1.9 \\
${ }^{241} \mathrm{Am}$ & 0.008786 & 0.008913 & 1.4 \\
\hline
\end{tabular}

This fluctuations of e.g. annual fluxes or fuel reprocessing capacity is one of the explanations of the discrepancies found between SEPAR and COSI6 results which are related to the Pu241 and Am241 that are investigated more in detail in Section 3.3.

The actual SEPAR outputs for this exercise are presented in Table 3.

This strategy leads to the simulation of equilibrium condition in COSI6, a non-trivial exercise without knowing the SEPAR outputs. The other SEPAR output of interest is the composition of the $\mathrm{Pu}$ vector in the MOX fresh fuel, shown in Table 4. This result has been compared with the COSI6 ones, showing a general good agreement. As expected, discrepancies have been found on the $\mathrm{Pu}$ vector, and ulterior tests have been done to better understand them. Since SEPAR relies on APOLLO2 calculations and COSI6 on CESAR, a comparison was performed between these two irradiation calculations, showing a general discrepancy in the $\mathrm{Pu}$ vector up to $2 \%$. The relative difference column of Table 4 has been calculated taking as reference the COSI6 values for 50 years (this condition has been taken as reference for this kind of comparison in this work, the statistic validation will be the subject for the next studies).

For what concerns the equilibrium simulation in COSI6, the strategy was to try to have 1 year of fuel fabrication capacity in the spent fuel and therefore to decrease from 10 years to 9 years of cooling, in order to exactly simulate the 10 years cooling as in SEPAR, as can be seen in Figure 4 . The same strategy has been adopted for the 2 


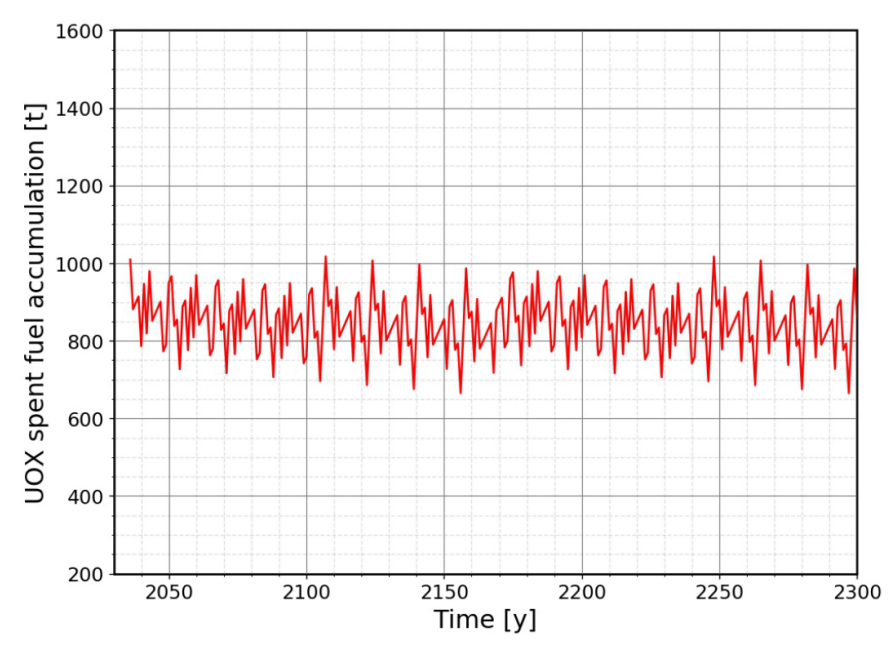

Fig. 4. COSI6 UOX spent fuel accumulation.

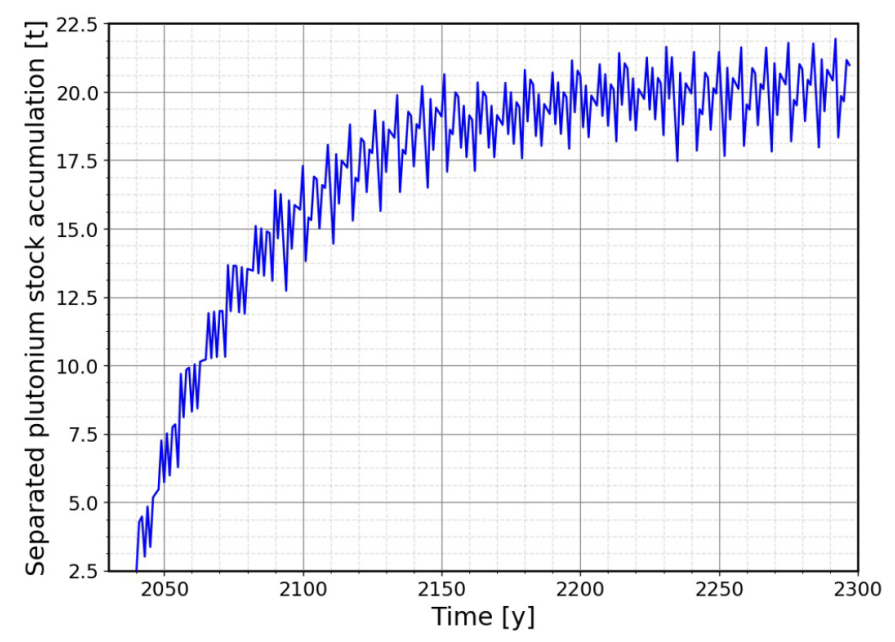

Fig. 5. COSI6 UOX - MOX Pu stock accumulation.

years aging time, this value was settled to 1 year in COSI6, and the target was to have 1 year of $\mathrm{Pu}$ flux availability in the separated $\mathrm{Pu}$ stock, as can be seen in Figure 5. The 10.56 tonnes of annual $\mathrm{Pu}$ flux have been calculated as the $12 \%$ (MOX Pu content) of 88.04 tonnes (MOX fuel fabrication capacity). Since the stabilization of the separated $\mathrm{Pu}$ stock is different between SEPAR and COSI6, the 50 year samples for the realization of Table 4 have been taken from 2040 to 2090, in which the average plutonium in the stock is 10.98. The discrepancies between 10.56 and 10.98 means that the COSI6 $\mathrm{Pu}$ vector is affected by around 2 weeks longer cooling time per year with respect to the SEPAR one. It explains the discrepancies on ${ }^{241} \mathrm{Pu}$ and ${ }^{241} \mathrm{Am}$ in the $\mathrm{Pu}$ vector. The reason is the relatively short half life of ${ }^{241} \mathrm{Pu}\left(t_{1 / 2}=14.3\right.$ year $)$, making these two isotopes very sensitive to the aging period.

\subsection{UOX-ERU mono-recycling}

A schematic representation of the UOX - ERU cycle option is shown in Figure 6. Generally, for given initial enrichment, ${ }^{235} \mathrm{U}$ content decreases with burnup. The

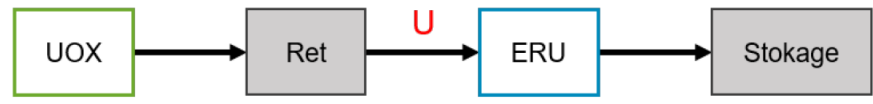

Fig. 6. Fuel cycle of a UOX - ERU fleet.

Table 5. COSI6/SEPAR comparison of reprocessed uranium isotopic vector after irradiation for the UOX-ERU mono-recycling option (heavy metal weight fraction).

\begin{tabular}{llll}
\hline Isotopes & SEPAR & COSI6 & Rel. Diff. [\%] \\
\hline${ }^{234} \mathrm{U}$ & 0.000201 & 0.000239 & 18.9 \\
${ }^{235} \mathrm{U}$ & 0.008081 & 0.008132 & 0.6 \\
${ }^{236} \mathrm{U}$ & 0.006798 & 0.006824 & 0.4 \\
${ }^{238} \mathrm{U}$ & 0.984921 & 0.984805 & 0.0 \\
\hline
\end{tabular}

${ }^{236} \mathrm{U}$ concentration increases with initial fuel enrichment and burnup since it is the product of neutron capture of ${ }^{235} \mathrm{U} .{ }^{236} \mathrm{U}$ is considered to be a neutron poison due to its thermal absorption cross section. The modified isotopic composition of reprocessed uranium poses two major hurdles for its re-use in a reactor: the high radiological impact caused by the presence of ${ }^{232} \mathrm{U}$ prohibits the easy handling of the material, making more radiological protection measures necessary [14], whereas the presence of ${ }^{236} \mathrm{U}$, in quantities similar to ${ }^{235} \mathrm{U}$, reduces the macroscopic fission cross section of the fuel, thus creating the need for overenriching in the ${ }^{235} \mathrm{U}$ isotope. Re-enrichment can happen either directly, in a gas centrifuge plant for example, but another possibility is to mix the reprocessed uranium with already enriched uranium to obtain the desired final enrichment. Alternatively, reprocessed uranium can also be used as a support for MOx fuel, decreasing the needed concentration of plutonium in the fuel due to the higher enrichment with respect to the depleted uranium that is normally used.

The SEPAR simulation converges with 0.899 UOX reactor fraction and 0.101 ERU. For what concerns the equilibrium simulation in COSI6, the strategy on the cooling and fabrication time was the same adopted in Section 3.1. Table 5 shows the comparison between the isotopic vector of reprocessed uranium simulated in COSI6 and SEPAR with the relative differences. The U235 enrichment value for fresh ERU fuels given by SEPAR is $5.235 \%$.

Two explanations can justify the consistent ${ }^{234} \mathrm{U}$ discrepancy: firstly, a 20\% APOLLO2 - CESAR relative difference has been found on the ${ }^{234} \mathrm{U}$ concentration after irradiation. Secondly, SEPAR doesn't consider decay chain longer than one parent and one daughter isotopes. Therefore the ${ }^{234} \mathrm{U}$ SEPAR value is lower because the contribution of ${ }^{242} \mathrm{Cm}$ (that decays in ${ }^{238} \mathrm{Pu}$ with $t_{1 / 2}=160 \mathrm{~d}$ and later in ${ }^{234} \mathrm{U}$ with $t_{1 / 2}=87 y$ ) is not taken into account at the moment. Even if this contribution is relatively low, the fact that the ${ }^{234} \mathrm{U}$ contribution of the uranium vector is also small, causes a considerable relative error between these 2 values. This longer decay chain functionality is on top of the future SEPAR development 


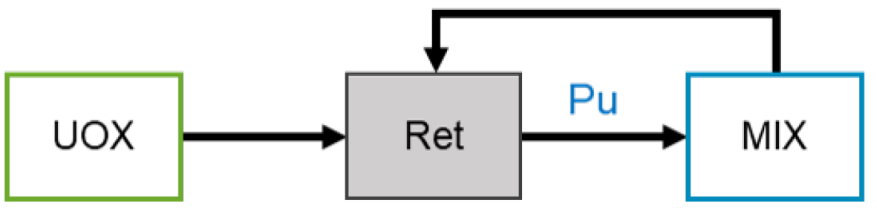

Fig. 7. Fuel cycle of a UOX - MIX fleet.

features. These two possible explanations will be investigated in the future in order to understand and reduce this discrepancy.

\subsection{UOX-MIX full multi-recycling}

A schematic representation of the UOX - MIX cycle option is shown in Figure 7. In this exercise the MIX fuel used has a discharged burnup of 50 GWday/t and 1404 days of EFPD for the whole irradiation time. All the plutonium from UOX/MIX spent fuel is supposed to be reprocessed and recycled to fabricate new MIX fuel, which helps to stabilize the plutonium inventory. This is a symbiotic equilibrium in the sense that all plutonium produced UOX fuels is net consumed in MIX batches $[15,16]$. However, there is a risk of producing significant quantities of minor actinides by capture on $\mathrm{Pu}$ isotopes (thermal neutron spectrum). The final objective of this exercise is to prove the SEPAR possibility to simulate a plutonium full multi-recycling.

The SEPAR simulation converges with 0.639 UOX reactor fraction and 0.361 MIX. For what concerns the equilibrium simulation in COSI6, the strategy of the cooling time was the same adopted in Section 3.1. To simulate the UOX - MIX equilibrium is a non-trivial exercise because of the complexity introduced by the full multirecycling condition. In principle, the equilibrium state can be reached by modifying the MIX core fraction given by SEPAR in COSI6 with dichotomy.

The system is difficult to simulate at equilibrium due to the fact that before recycling the MIX fuel, the plutonium extracted from spent fuel is saved in separated $\mathrm{Pu}$ stock, as can be seen in Figure 8. Therefore, the separated plutonium inventory should be non-zero constant at equilibrium state, while it oscillates during dynamic simulations.

Regarding the 2 years aging time in SEPAR, the strategy in COSI6 was to reach these 2 years by the sum of the fabrication time and the time the plutonium spends in the separated stock. As can be seen in Figure 8, since the average amount of plutonium in the separated stock is 6 tonnes, to reach the 2 years of aging time, the fabrication time in COSI6 was set to 1.8 years as the result of the following formula:

$$
\begin{aligned}
& t_{\text {Fab } b_{C O S I 6}}=t_{\text {aging }} \text { SEAR } \\
& t_{\text {Fab }}-\frac{m_{P u_{C O S I 6}}}{\Phi_{P u_{C O S I 6}}} \\
& =2-6 / 30=1.8 y
\end{aligned}
$$

in which $m_{P u_{C O S I 6}}$ represents the plutonium average mass in the separated stock.

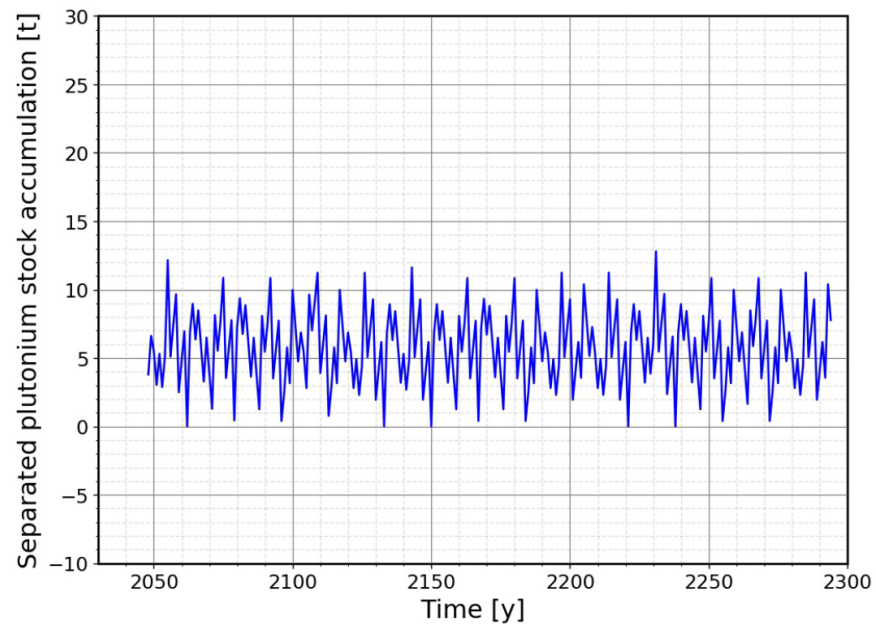

Fig. 8. COSI6 UOX - MIX Pu stock accumulation.

Table 6. COSI6/SEPAR comparison of fresh MIX fuel $\mathrm{Pu}$ vector for the UOX-MIX full multi-recycling option (heavy metal weight fraction).

\begin{tabular}{llll}
\hline Isotopes & SEPAR & COSI6 & Rel. Diff. [\%] \\
\hline${ }^{238} \mathrm{Pu}$ & 0.043815 & 0.047483 & 7.7 \\
${ }^{239} \mathrm{Pu}$ & 0.354130 & 0.358794 & 1.3 \\
${ }^{240} \mathrm{Pu}$ & 0.276968 & 0.271273 & 2.4 \\
${ }^{241} \mathrm{Pu}$ & 0.085268 & 0.084290 & 1.2 \\
${ }^{242} \mathrm{Pu}$ & 0.231889 & 0.230849 & 0.5 \\
${ }^{241} \mathrm{Am}$ & 0.008647 & 0.008832 & 2.1 \\
\hline
\end{tabular}

The other SEPAR result is the composition of the plutonium vector in the MIX fresh fuel, shown in Table 6. This result has been compared with the COSI6 ones, showing a general good agreement. The biggest different found is on the ${ }^{238} \mathrm{Pu}$. A discrepancy of $2.2 \%$ has been already found in Table 4 regarding the UOX - MOX mono-recycling case, therefore this difference can be the result of the error propagation due to several recycling.

\subsection{UOX-MOX-AMR}

A schematic representation of the UOX - MOX - AMR cycle option is shown in Figure 9, where $s$ represent the AMR fuel fraction directed to the reprocessing plant Ret1, while $\epsilon$ is the fraction of recycled MOX fuel.

There is currently no recycling strategy implemented for used MOX fuel, which is accumulating in storage. They can't be entirely multirecycled into new MOX assemblies, because the low plutonium grade of used MOX fuel would require high plutonium content, over the generally accepted upper limit of $12 \%$. A strategy under study is the use of sodium fast reactors, but they are reputed more expensive than their PWR counterpart. A way to reduce their cost currently consists to reduce their size. In this example, a fixed reduced fraction (5\% of the installed electrical power) of Small Modular Fast Reactors (called SMR-Na in [17], here called AMR) are added to a UOX 


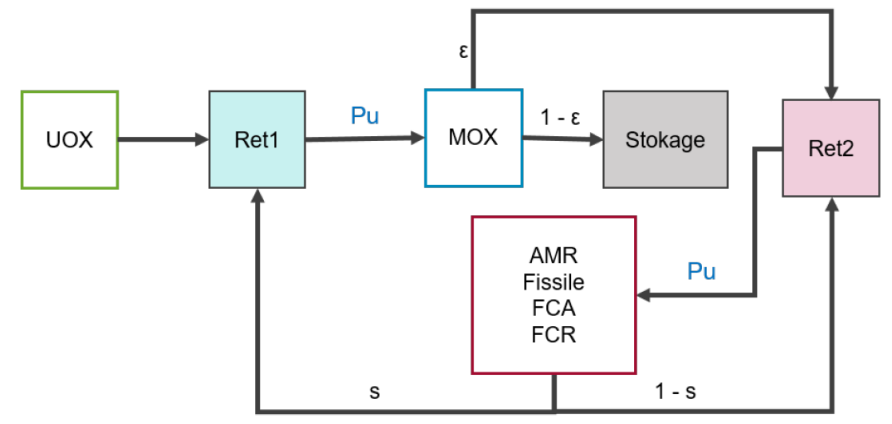

Fig. 9. Fuel cycle of a AMR - UOX - MOX fleet.

Table 7. Main characteristics of the reactors featured in the UOX - MOX - AMR example.

\begin{tabular}{llll}
\hline Reactors & UOX & MOX & AMR \\
\hline Thermal power (MWth) & 4590 & 4590 & 400 \\
Electrical power (MWe) & 1650 & 1650 & 160 \\
Full core mass (t) & 129 & 129 & 19.2 \\
Burnup (GWday/t) & 50 & 46 & 65 \\
EFPD & 1404 & 1293 & 900 \\
Load factor & 0.83 & 0.83 & 0.90 \\
Fuel fractioning & 3 & 3 & 4 \\
Cooling time (y) & 5 & 5 & 5 \\
Fabrication time (y) & 2 & 2 & 2 \\
\hline
\end{tabular}

- MOX fleet. The AMR core is slightly breeder, thanks to its radial and axial fertile blankets (10.55 and 3.48 $\mathrm{t}$ respectively). The main characteristics of the reactors involved in this fleet are compiled in Table 7.

The retreatment plant Ret1 supplies MOX new assemblies in plutonium while Ret2 is dedicated to new AMR fuel assemblies. The fraction $s$ of used AMR fuel, blankets included, is directed toward Ret1, the rest supplies Ret2. MOX used fuel only supplies Ret2. The fabrication and cooling times are 2 and 5 years respectively.

The goal is to maximize the fraction of recycled MOX fuel ( $\epsilon$ in Fig. 9) while verifying cycle constraints. Thanks to its short calculation time, SEPAR can be used iteratively to solve this sort of optimization problems. The main results of this case are compiled in Tables 8 and 9 . At best $70 \%$ of used MOX is recycled. The entirety of the used AMR fuel is directed toward MOX fabrication. The plutonium content constraint is not reached, which implies that the identified equilibrium is limited by mass, and not plutonium isotopy. SEPAR would allow for the differentiation of the retreatment of fertile blankets, for example to prioritize them for MOX retreatment. This possibility is not touched on in this paper because the plutonium grade is not the limiting factor.

This last case shows the adaptability of SEPAR to simulate complex systems. The validation of the results concerning the UOX - MOX - AMR cycle has not been tested yet with COSI6, it will be the interest for the next studies.
Table 8. UOX - MOX - AMR fleet equilibrium main characteristics.

\begin{tabular}{ll}
\hline Results & $\%$ \\
\hline Pu content in MOX & 11.30 \\
UOX & 79.16 \\
MOX & 15.84 \\
AMR & 5 \\
$\epsilon$ & 70 \\
$\mathrm{~s}$ & 100 \\
\hline
\end{tabular}

Table 9. SEPAR fresh fuel Pu vector for the UOX - MOX - AMR option (heavy metal weight fraction).

\begin{tabular}{lll}
\hline Isotopes & SEPAR MOX & SEPAR AMR \\
\hline${ }^{238} \mathrm{Pu}$ & 0.022927 & 0.028098 \\
${ }^{239} \mathrm{Pu}$ & 0.487713 & 0.372820 \\
${ }^{240} \mathrm{Pu}$ & 0.294205 & 0.334450 \\
${ }^{241} \mathrm{Pu}$ & 0.079473 & 0.110506 \\
${ }^{242} \mathrm{Pu}$ & 0.107623 & 0.142920 \\
${ }^{241} \mathrm{Am}$ & 0.008059 & 0.011206 \\
$\mathrm{PuCi}$ & 0.112964 & 0.297742 \\
\hline
\end{tabular}

\section{Conclusion}

This paper aims to present for the first time the new equilibrium simulation tool SEPAR (Equilibrium Simulator of Advanced Reactor Parks) developed at the Department of Reactor Studies (DER) at CEA Cadarache. It was applied to different fuel cycle options to show how they are modeled and the type of results the SEPAR tool is actually able to produce.

Equilibrium state is the weak point of dynamic scenario codes. Industries are particularly interested in steady state conditions, especially for radioactive stock dimensioning, fabrication and reprocessing facilities, etc. SEPAR can find a unique equilibrium condition (if physically possible) that later can be simulated as a result of a fleet evolution with a dynamic code. Therefore, it can be said that equilibrium codes cannot substitute dynamic codes, while instead they can be seen as complementary tools.

The presentation of the SEPAR outputs is accompanied by the first estimate of validation. The validation work was done for the first three cases by comparing the SEPAR outputs with COSI6 simulations. It has been shown a good agreement for the main SEPAR/COSI6 results. In order to better understand and reduce the discrepancies found between the two methods, new advanced cycle options and further validations of the presented cases will be done. SEPAR is the new tool that allows to study nuclear fleets at equilibrium, precision improvements and additional modules will be added in the future.

\section{Author contribution statement}

All the authors were involved in the preparation of the manuscript. All the authors have read and approved the final manuscript. 


\section{References}

1. Ministère de la transition écologique et solidaire. Programmation pluriannuelle de l'énergie. fr. p. 400. https://www.ecologie.gouv.fr/sites/default/files/PPEExecutive\%20summary.pdf

2. G. Krivtchik, P. Blaise, C. Coquelet-Pascal, Artificial neural network surrogate development of equivalence models for nuclear data uncertainty propagation in scenario studies, EPJ Nucl. Sci. Technol. 3, 22 (2017)

3. C. Coquelet-Pascal, M. Tiphine, G. Krivtchik, D. Freynet, C. Cany, R. Eschbach, C. Chabert, COSI6: a tool for nuclear transition scenario studies and application to SFR deployment scenarios with minor actinide transmutation, Nucl. Technol. 192, 91 (2015)

4. D. Minière, Urenco to enrich reprocessed uranium, https://www.world-nuclear-news.org/Articles/ Urenco-to-enrich-reprocessed-uranium (2018) [Online; accessed 16-June-2021]

5. G. Martin, M. Tiphine, C. Coquelet-Pascal, French transition scenarios toward a symbiotic nuclear fleet, in International Congress on Advances in Nuclear Power Plants (ICAPP - 2016) (San Francisco, United States, 2016), https://hal-cea.archives-ouvertes.fr/cea02509781

6. A. Culot, MOx Strategy and the future of French nuclear plants, https://imtech.wp.imt.fr/en/2019/06/ 18/mox-strategy-french-nuclear-plants/ (2019), [Online; accessed 17-June-2021]

7. F. Courtin, B. Leniau, N. Thiollière, B. Mouginot, X. Doligez, A. Somaini, A.A. Zakari-Issoufou, S. David, A. Bidaud, J.B. Clavel, Neutronic predictors for PWR fuelled with multi-recycled plutonium and applications with the fuel cycle simulation tool CLASS, Prog. Nucl. Energy 100, 33 (2017)

8. M. Ernoult, S. David, X. Doligez, O. Meplan, B. Leniau, A. Bidaud, A. Nuttin, B. Mouginot, J. Wilson, N. Capellan et al., Advanced plutonium management in PWR, complementarity of thorium and uranium, Progr. Nucl Energy 78, 330 (2015)

9. G. Martin, C. Coquelet-Pascal, Symbiotic equilibrium between sodium fast reactors and pressurized water reactors supplied with MOX fuel, Ann. Nucl. Energy 103, 356 (2017)

10. C. Broyden, A Class of Methods for Solving Nonlinear Simultaneous Equations (1965), http://pi.math.cornell.edu/ $\sim$ web6140/Broyden_965.pdf

11. J.M. Vidal, R. Eschbach, A. Launay, C. Binet, J.F. Thro, in CESAR5.3: an industrial tool for nuclear fuel and waste charactherization with associated qualification (2012), p. 15

12. G. Youinou, A. Vasile, Plutonium multirecycling in standard PWRs loaded with evolutionary fuels, Nucl. Sci. Eng. 151, 25 (2005)

13. G. Martin, M. Guyot, F. Laugier, G. Senentz, G. Krivtchik, B. Carlier, D. Lecarpentier, F. Descamps, C. Chabert, R. Eschbach, French scenario toward fast plutonium multirecycling in $\mathrm{PWR}$, in $I C A P P$, 2018, Charlotte, United States (2018), p. 11

14. W.B. Arthur, Uranium-232 production in current design LWRS, Tech. rep. (1997), https://www.osti.gov/servlets/ purl $/ 5963522$

15. G. Martin, Study of a mixed fleet of breeder SFR and EPR supplied with LEU and MOX fuels to balance the plutonium inventory, in ICAPP, 2018, Charlotte, United States (2018), p. 6

16. OECD Nuclear Energy Agency, Plutonium management in the medium term: a review by the OECD/NEA working party on the physics of plutonium fuels and innovative fuel cycles (WPPR) (Nuclear Energy Agency, Organisation for Economic Co-operation and Development, Issy-lesMoulineaux, France, 2003), ISBN 978-92-64-02151-8, oCLC: 61895662

17. K. Tirel, T. Kooyman, C. Coquelet-Pascal, E. Merle, Possibility to stabilize plutonium inventory in a sodium-cooled small modular reactors - Pressurized water reactors fleet, Ann. Nucl. Energy 146, 107632 (2020)

Cite this article as: Heddy Barale, Camille Laguerre, Paul Sabatini, Fanny Courtin, Kévin Tirel and Guillaume Martin, A new tool for the simulation of different nuclear fleets at equilibrium, EPJ Nuclear Sci. Technol. 8, 1 (2022) 